\title{
Announcement: Remote Sensing 2017 Best Reviewer Award Winners
}

\section{Remote Sensing Editorial Office}

Multidisciplinary Digital Publishing Institute, Alban-Anlage 66, 4052 Basel, Switzerland; remotesensing@mdpi.com

Received: 1 February 2018; Accepted: 3 February 2018; Published: 7 February 2018

Peer review is an essential part of the publication process, ensuring that Remote Sensing maintains the high standard of its published papers. Thanks to our reviewers, the median time from submission to first decision has been reduced to 28 days.

The following referees have been selected by the Editor-in-Chief of Remote Sensing, Prof. Prasad Thenkabail, to receive the "Remote Sensing 2017 Best Reviewer Award" based on the quantity, timeliness and quality of their reviews in 2017. The top three will receive $500 \mathrm{CHF}$, publication of a Feature Paper in Remote Sensing free of charge and a certificate. The other referees will be awarded publication of a Feature Paper in Remote Sensing free of charge and a certificate.
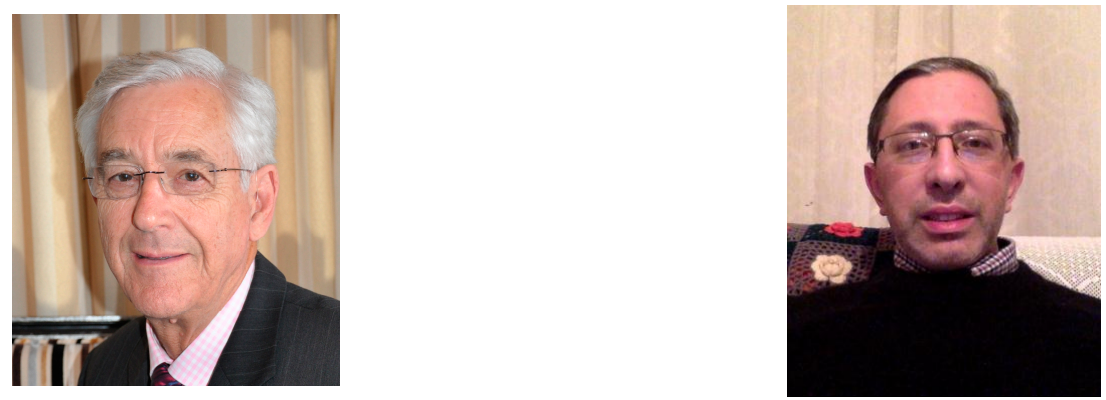

Dr. John C. Trinder

The University of New South Wales, Australia

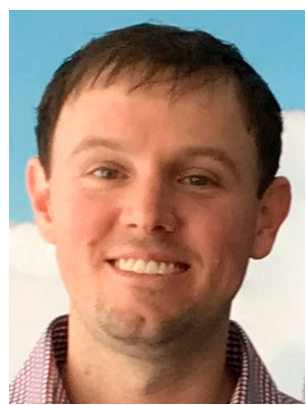

Dr. Antonio Pepe

Consiglio Nazionale delle Ricerche, Italy
Dr. Brian Johnson

Institute for Global Environmental Strategies, Japan

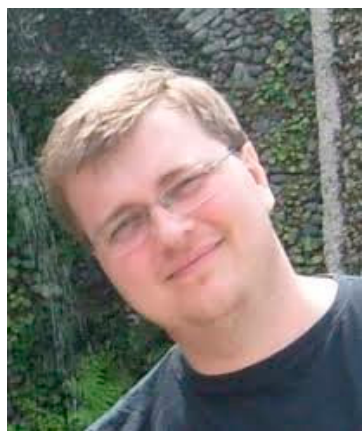

Dr. Veraldo Liesenberg Santa Catarina State University, Brazil 

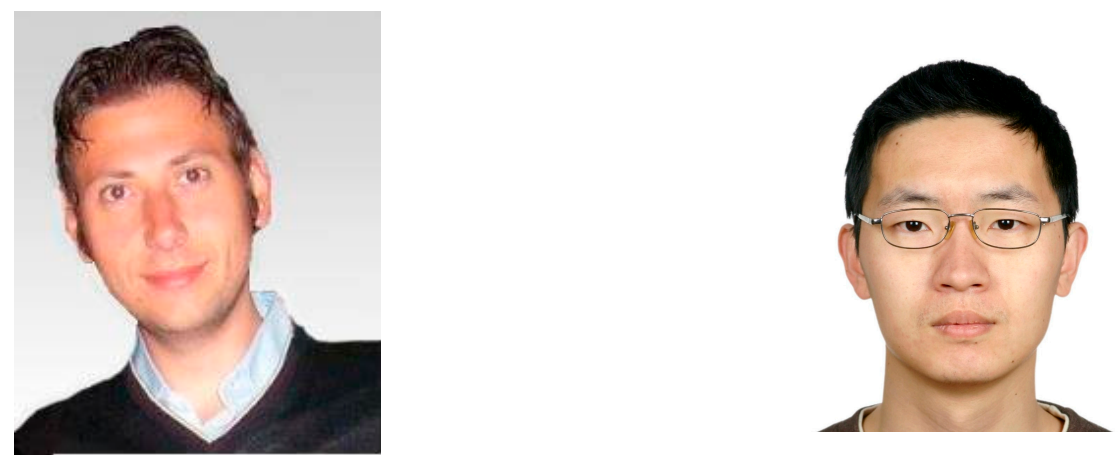

Dr. Andrea Buono

Università degli Studi di Napoli “Parthenope", Italy

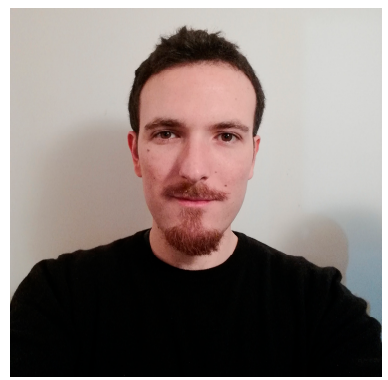

Dr. Antonio Novelli

Politecnico di Bari, Italy
Dr. Jinyang Du

University of Montana, USA

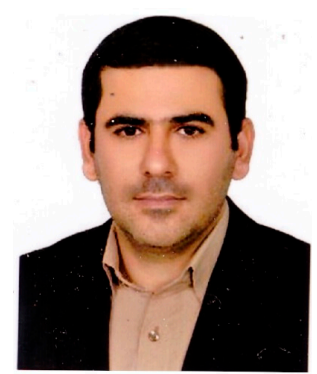

Dr. Saeid Gharechelou

Chiba University, Japan

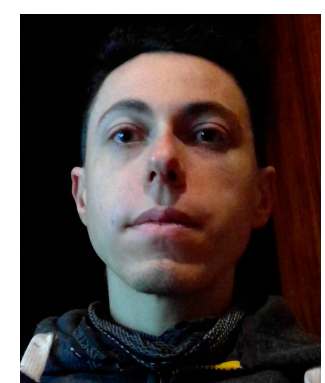

Dr. Loris Nanni

University of Padua, Italy

Dr. Liming He

University of Toronto, Canada

On behalf of the Remote Sensing editorial board members and editorial staff, we wish to congratulate the ten outstanding reviewers for their accomplishments.

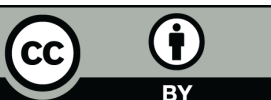

(C) 2018 by the author. Licensee MDPI, Basel, Switzerland. This article is an open access article distributed under the terms and conditions of the Creative Commons Attribution (CC BY) license (http:/ / creativecommons.org/licenses/by/4.0/). 